\title{
DIFERENTES EFEITOS DOS VÍNCULOS POLÍTICOS E DE BENEFÍCIOS FISCAIS NA GERAÇÃO DE VALOR ADICIONADO
}

\author{
André Carlos Einsweiller 1 \\ Cristian Baú Dal Magro 2 \\ Sady Mazzioni 3
}

- Artigo recebido em: 04/08/2019 -- Artigo aceito em: 02/04/2020 -.' Segunda versão aceita em: 02/05/2020

\section{RESUMO}

O estudo tem o objetivo de verificar se os vínculos políticos influenciam os benefícios fiscais e os seus diferentes efeitos na geração de valor adicionado de companhias listadas na B3. A amostra da pesquisa compreendeu 288 empresas brasileiras listadas na B3, totalizando 1.092 observações, no período de 2014 a 2017. Para a análise dos dados, foi utilizado dados em painel com efeitos fixos de setor e ano pela correção de white com uso do software STATA ${ }^{\circledR}$. Os resultados sugerem que as empresas com conexão política e board interlocking pela expertise política intensificam o uso de benefícios fiscais. Por outro lado, empresas com conexão política apresentam menor geração de valor adicionado, enquanto aquelas que utilizam benefícios fiscais, mas não possuem conexões políticas, apresentaram maior geração de valor adicionado. Os resultados contribuem ao alertar os gestores, investidores e governo sobre os efeitos maléficos das conexões políticas na geração de valor adicionado, mesmo quando existe a utilização de benefícios fiscais, o qual, deveria melhorar a geração de valor adicionado às partes interessadas. Isso se comprovou pela influência direta dos benefícios fiscais na geração de valor adicionado. Para que as organizações alcancem uma geração de valor adicionado compatível com

\footnotetext{
1 Mestre em Ciências Contábeis e Administração pela Universidade Comunitária da Região de Chapecó (UNOCHAPECÓ). Professor do Curso de Graduação em Ciências Contábeis da Universidade do Oeste de Santa Catarina (UNOESC). Endereço: Rua Bélgica, $n^{\circ} 145$, Loteamento Jardim Europa, Bairro Flor da Serra, Joaçaba/SC, Brasil, CEP 89.600-000. Telefone: (49) 99118-8318. E-mail: einsweiller@unochapeco.edu.br.
} https://orcid.org/0000-0001-9556-6952

2 Doutor em Ciências Contábeis e Administração pela Universidade Regional de Blumenau (FURB). Professor do Programa de Pós-Graduação em Ciências Contábeis e Administração da Universidade Comunitária da Região de Chapecó (UNOCHAPECÓ). Endereço: Servidão Anjo da Guarda, n² 295 - D, Bairro EFAPI, Chapecó/SC, Brasil, CEP 89.809-900. Telefone: (49) 991182003. E-mail: crisbau@unochapeco.edu.br.

https://orcid.org/0000-0002-7609-5806

3 Doutor em Ciências Contábeis e Administração pela Universidade Regional de Blumenau (FURB). Professor do Programa de Pós-Graduação em Ciências Contábeis e Administração da Universidade Comunitária da Região de Chapecó (UNOCHAPECÓ). Endereço: Servidão Anjo da Guarda, n² 295 - D, Bairro EFAPI, Chapecó/SC, Brasil, CEP 89.809-900. Telefone: (49) 999289520. E-mail: sady@unochapeco.edu.br.

https://orcid.org/0000-0002-8976-6699

Editor responsável pela aprovação do artigo: Dr. Ewerton Alex Avelar Editora responsável pela edição do artigo: Dr ${ }^{a}$. Bruna Camargos Avelino 
as aspirações do governo na oferta de benefícios fiscais, se torna necessário o adequado investimento dos recursos pelas empresas e o monitoramento dos interesses particulares dos indivíduos com vínculos políticos, que estão no conselho de administração e/ou são acionistas com participação relevante no capital.

Palavras chave: Conexão Política. Board interlocking pela Expertise Política. Benefícios Fiscais. Geração de Riqueza.

\title{
DIFFERENT EFFECTS OF POLITICAL LINKS AND TAX BENEFITS ON THE ADDED VALUE GENERATION
}

\begin{abstract}
The study aims to verify whether political ties influence tax benefits and their different effects on the generation of value added for companies listed on B3. The research sample comprised 288 Brazilian companies listed on B3, totaling 1,092 observations, from 2014 to 2017. For data analysis, panel data used with fixed sector and year effects by white correction using the STATA software $\AA$. The results suggest that companies with political connections and board interlocking due to political expertise intensify the use of tax benefits. On the other hand, companies with a political connection have a lower generation of added value, while those that use tax benefits, but do not have political connections, presented a higher generation of added value. The results contribute to alert managers, investors and the government about the harmful effects of political connections in the generation of value added, even when there is the use of tax benefits, which should improve the generation of value added for interested parties. This proven by the direct influence of tax benefits on the generation of value added. For organizations to achieve a generation of value added compatible with the aspirations of the government in offering tax benefits, it is necessary to adequately invest resources by companies and monitor the private interests of individuals with political ties, who are on the Board of Directors and/or are shareholders with a relevant stake in the capital.
\end{abstract}

Keywords: Political Connection. Board interlocking by Political Expertise. Tax benefits. Wealth generation.

\section{INTRODUÇÃO}

O processo de desenvolvimento do Brasil foi marcado por um modelo centralizador de riquezas, intensificado pelo desenvolvimento industrial tardio no país, com ciclos econômicos desarticulados e um desordenado processo de urbanização das cidades. Entretanto, em função de condições geográficas e econômicas desfavoráveis, algumas regiões foram favorecidas em maior escala pelos entes públicos (Luca \& Lima, 2007).

Desde o fim da década de 1980, existe um conflito fiscal entre os Estados, motivado pela Constituição Federal de 1988, que estabeleceu, aos Estados, o poder de fixar alíquotas do Imposto sobre Circulação de Mercadorias e Serviços 
(ICMS). Com a busca do desenvolvimento e atração de investimentos, criou-se um eixo político para ações e reações desordenadas de guerra fiscal entre os Estados (Dulci, 2002).

A Constituição Federal de 1988, em seu art. $3^{\circ}$, definiu que entre os objetivos fundamentais da República Federativa do Brasil estão a erradicação da pobreza e da marginalização, a redução das desigualdades regionais e sociais (Brasil, 2008). Para equalizar as desigualdades sociais, os entes governamentais adotam políticas fiscais que beneficiam determinados setores da economia. As normas tributárias, quando utilizadas como benefícios fiscais, revelam-se potenciais para que os entes governamentais atendam áreas sociais prioritárias. Portanto, a função arrecadatória dos tributos assume papel secundário, dando espaço aos benefícios fiscais como medida de indução econômica (Assunção, 2011).

A Lei Complementar (LC) n. 160, de 07 de agosto de 2017, disciplina a forma de convalidação dos benefícios fiscais (Brasil, 2017). As inclusões dos parágrafos $4^{\circ}$ e $5^{\circ}$ no art. 30 da Lei $n^{\circ} .12 .973 / 2014$, classificaram todos os benefícios fiscais decorrentes do Imposto sobre Operações relativas à Circulação de Mercadorias e Prestação de Serviços de Transporte Interestadual e Intermunicipal e de Comunicação (ICMS) como subvenções para investimento, desde que cumpridos determinados requisitos, gerando efeitos fiscais relacionados à incidência de tributos federais, inclusive com efeitos retroativos (Brasil, 2014). O objetivo da legislação é induzir as empresas a utilizar os benefícios fiscais para reinvestimento, expansão e competitividade, fatores que geram maior valor adicionado para as partes envolvidas.

Ao mesmo tempo que os benefícios fiscais podem gerar indução econômica e social, há também uma renúncia de receita dos entes públicos (Afonso, Silveira, Carvalho, Kintowitz \& Azevedo, 2014), emergindo o debate sobre o efetivo retorno social e econômico das empresas privadas que se utilizam de benefícios fiscais. Neste cenário, Kronbaver, Schneider, Lumbieri, Pereira e Zani (2011) sugerem que as empresas com incentivos fiscais retornam para a sociedade local um valor adicionado superior ao que seria investido pelo próprio governo. Contudo, Matkin (2010) argumenta que as políticas de incentivos fiscais, muitas vezes, não surtem efeitos positivos, pois não afetam as decisões de investimento das empresas.

Outro aspecto relevante advém dos vínculos políticos e sua relação com o uso dos benefícios fiscais. O vínculo político pode ser caracterizado pela participação de indivíduos, que possuem ligação com o governo, no conselho de administração (CA) de empresas privadas, denominado de conexão política. Nos casos em que a participação desses indivíduos no CA é simultânea em mais de uma empresa tem-se o denominado de board interlocking pela expertise política (Dal Magro \& Klann, 2020).

A existência da conexão política também pode ocorrer quando algum membro do CA tenha ocupado posição no senado, na câmara dos deputados, na diretoria de alguma empresa ligada ao governo ou tenha sido nomeado para alguma função pública (Boubakri, Cosset \& Saffar, 2008; Chaney, Faccio \& Parsley, 2011; Camilo, Marcon \& Bandeira-de-Mello, 2012). Os vínculos políticos incluem, ainda, casos em que o próprio político é um grande acionista, ou diretor chefe de empresas privadas (Chaney, Faccio \& Parsley, 2011). 
Vários podem ser os motivos que levam as empresas privadas a se conectarem politicamente (Faccio, 2006), dentre eles a busca de favores do governo e a presumida distância de ameaças à organização (Baysinger, 1984; Pffefer \& Salancik, 2003). A Teoria da Dependência de Recursos considera o ambiente como fonte de influência nas empresas. Sob tal perspectiva, a empresa luta contra ameaças externas e a escassez de recursos, tendo o componente político impacto no processo de captação (Aldrich \& Pffefer, 1976). A Teoria da Dependência de Recursos também é útil para explicar que os vínculos políticos podem ser utilizados para captação de benefícios às empresas, a exemplo dos benefícios fiscais.

Sob a perspectiva da Teoria da Dependência de Recursos há justificativa para as empresas se conectarem politicamente quando possuem dependência interfirmas (ou governamental) na consecução de suas atividades (Pffefer \& Salancik, 2003). Como consequência, a dependência oferece risco e incerteza, podendo afetar o desempenho das empresas (Boubakri, Cosset \& Saffar, 2008; Okhmatovskiy, 2010; Camilo, Marcon \& Bandeira-de-Mello, 2012).

Os políticos, ao canalizar os recursos às empresas conectadas, podem aumentar os investimentos, mas abrir espaço para a corrupção (Shleifer \& Vishny, 1997). A Teoria da Agência oferece uma compreensão para a relação contratual entre os proprietários e gestores, bem como, os conflitos dessa relação (Godoy \& Marcon, 2008; Silveira \& Barros, 2008). Além do conflito que envolve o gestor e o acionista, a Teoria da Agência pode ser estendida a outros conflitos de expropriação de riqueza do principal pelo agente (Borini \& Luchesi, 2007).

Os problemas de agência são ampliados pelas relações políticas (Infante \& Piazza, 2014), tornando-se maiores quando envolve relação entre principal e agente com vínculos políticos (Weymer \& Castor, 2009). Nestes casos, os gestores de empresas que possuem vínculos políticos expropriam os proprietários, utilizando os recursos para finalidades opostas aos anseios dos acionistas (Faccio, 2006; Chen, Gu, Kubota \& Takehara, 2015; Dal Magro, 2017).

Deste modo, a empresa presume que o governo possui recursos atrativos e desenvolve estratégia política com a finalidade de obter e preservar influências sobre as políticas públicas do governo (Hillman \& Hitt, 1999). Não obstante, os vínculos políticos influenciam o desempenho e são importantes num ambiente competitivo. Cunha, Ribeiro e Santos (2005) comentam que o desempenho das entidades pode ser avaliado pela geração de riqueza oriunda da demonstração do valor adicionado (DVA), calculada pela diferença entre o valor das vendas e os consumos intermediários adquiridos de terceiros, em determinado período.

Frente ao exposto, apresenta-se o seguinte problema de pesquisa: qual a influência dos vínculos políticos nos benefícios fiscais e os seus diferentes efeitos na geração de valor adicionado de companhias listadas na $[\mathrm{B}]^{3}$ ? Para responder ao problema de pesquisa, o estudo tem por objetivo verificar se os vínculos políticos influenciam os benefícios fiscais e os seus diferentes efeitos na geração de valor adicionado de companhias listadas $n a[B]^{3}$.

O estudo justifica-se em razão de que ainda não existem evidências que comprovem a efetividade dos benefícios fiscais em promover o desenvolvimento econômico por meio das organizações privadas (Oliveira, Cunha, Nascimento \& Avelino, 2014), tampouco o próprio benefício desses incentivos para o 
crescimento e expansão das organizações, observada, neste caso, pela ampliação na geração do valor adicionado.

Estudos anteriores evidenciaram melhorias no desempenho econômico de empresas que utilizam benefícios fiscais (Kronbaver et al., 2011). Outros analisaram, isoladamente, a relação entre conexão política e o desempenho das empresas (Camilo et al., 2012; Pinheiro \& De Luca \& Vasconcelos, 2016; Cruz \& Parente, 2018; Silva, Xavier, Gambirage \& Camilo, 2018). A geração de valor adicionado também foi considerada em outras investigações, contudo, estudos utilizando fatores explicativos da criação de riqueza com amostras de empresas listadas, não oriundas de setor específico ou estudos de caso, são mais escassas. Exceções podem ser atribuídas aos estudos de Bianchet, Zanin, Mazzioni e Moura (2019) que investigaram a influência das empresas familiares e não familiares; e, Mazzioni, Carpes e Lavarda (2014) que consideraram o grau de intangibilidade, para explicar a geração de valor adicionado.

A originalidade do estudo consiste em utilizar os efeitos dos vínculos políticos e benefícios fiscais, de forma conjunta, para explicar a geração de valor adicionado como medida de desempenho. As evidências indicaram que os vínculos políticos auxiliam as empresas no compartilhamento de informações sobre o acesso aos benefícios fiscais, contudo, potencializam os conflitos de agência e reduzem a geração de valor adicionado.

\section{VÍNCULOS POLIITICOS, BENEFÍCIOS FISCAIS E VALOR ADICIONADO}

As conexões políticas desempenham importante papel no contexto econômico mundial, tornando-se um recurso valioso para muitas empresas (Fisman, 2001). Em geral, as empresas apresentam conexões políticas quando há ligações com o governo por intermédio dos executivos, controladores ou membros do board. Para efetivação das conexões políticas, as empresas utilizam de alguns mecanismos, como: empresários que também são políticos, vínculos de parentesco com políticos, doações às campanhas políticas, contratação de políticos para os conselhos administrativos, dentre outros (Bandeira-De-Mello \& Marcon, 2011).

Além disso, a conexão política pode emergir quando: (i) o governo é acionista de grandes grupos empresariais; (ii) o empresário entra na política ou é indicado para cargo de governo; (iii) políticos aposentados fazem parte de conselhos das empresas ou assumem cargos executivos; (iv) empresas realizam doações às campanhas políticas; e (v) empresários estabelecem seus próprios canais com o governo (Bandeira-De-Mello \& Marcon, 2011).

As conexões políticas afetam o potencial de crescimento de uma empresa e o valor econômico de seus ativos. Destaca-se, por exemplo, o faturamento e o valor de uma fábrica que, provavelmente, serão dependentes da existência da conexão política na garantia de possíveis negócios futuros. Todavia, o valor dessas relações não é refletido pela contabilidade, mas tende a ser bastante manifestada na concessão privilegiada de contratos governamentais e no tratamento preferencial das políticas governamentais (Fan, Guan, Li \& Yang, 2014).

A relação entre empresa e o governo pode favorecer o alcance de desempenho superior ao das estratégias de mercado tradicionais (Barney, 1986; 
Camilo et al., 2012). As conexões políticas também estão relacionadas com a sobrevivência das empresas, principalmente aquelas que são altamente reguladas (Pfeffer \& Salancik, 2003). De acordo com a proposição da Teoria da Agência, as empresas buscam favores do governo e garantias por meio das conexões políticas (Baysinger, 1984; Pfeffer \& Salancik, 2003).

Aldrich e Pfeffer (1976) observam que a relação entre a empresa e o ambiente é um processo de troca. Se as empresas não podem promover os recursos necessários, então devem supri-los interagindo com o ambiente. Nesse sentido, Pearce (1983) argumenta que as conexões políticas podem servir como mecanismo de resposta à competitividade, captando recursos vitais para obtenção de melhor desempenho. Camilo et al. (2012) e Silva et al. (2018) sugerem que as conexões políticas oferecem recursos informacionais. A presença de políticos no CA das empresas privadas pode favorecer o compartilhamento de informações para acesso aos diferentes benefícios fiscais.

Deste modo, tais considerações levam a proposição da seguinte hipótese: $H_{1}$ - Empresas com maior presença de políticos no conselho de administração são mais propensas a ter acesso aos benefícios fiscais.

A participação de indivíduos políticos no CA de empresas privadas pode ser caracterizada pela conexão política. As empresas estão conectadas com um político quando o seu maior acionista ou representante é parlamentar ou ministro chefe de Estado. A conexão política também ocorre se um membro do CA ocupou posição parlamentar, assumiu a diretoria de uma empresa conectada ao governo ou foi nomeado para qualquer função pública (Faccio, 2006; Fan, Whong \& Zang, 2007; Goldman, Rocholl \& So, 2008; Boubakri, Guedhami, Mishra \& Saffar, 2012). A ligação da empresa com o governo pode ser exercida pela nomeação de políticos e/ou ex-políticos no CA (Hillman, 2005).

Caso haja participação simultânea desses indivíduos no CA de várias empresas, denomina-se de board interlocking (BI) pela expertise política (Dal Magro \& Klann, 2020). O BI refere-se a uma relação social criada entre duas ou mais empresas por meio da inclusão de um mesmo profissional no CA (Battiston, Weisbuch \& Bonabeau, 2003; Albuquerque, 2015). O fenômeno Bl surge quando um profissional da alta administração de determinada empresa ocupa cargo no CA de outra companhia (Santos \& Silveira, 2007) ou quando dois órgãos sociais compartilham pelo menos um diretor em comum (Wong, Gygax \& Wang, 2015). $\mathrm{O} \mathrm{Bl}$ está mais presente, justamente, entre os conselheiros de administração, os quais estão envolvidos com as diretorias e possuem outras atribuições institucionais do alto escalão (Santos, Silveira \& Barros, 2012).

Sendo assim, outro possível vínculo político do conselho de administração ocorre no board interlocking pela expertise política, como observado por Dal Magro e Klann (2020). O BI pode fazer com que as empresas tenham facilidade no acesso às informações, fontes de recursos financeiros e privilégios na disputa pela preservação dos recursos (Johnson, Daily \& Ellstrand, 1996; Faccio, 2006). A pouca atenção ao Bl pode culminar em práticas oportunistas, a exemplo daquelas de ordem estratégica e operacional (Dal Magro, 2017).

As empresas com vínculos políticos podem ter maior proteção no uso do board interlocking para escolhas contábeis mais agressivas (Riahi-Belkaovi, 2004) e tratamento diferenciado por parte do governo (Khwaja \& Mian, 2005; Faccio, 2006). A prática de interlocking permite o entrelaçamento de empresas pela 
relação de seus conselheiros, aumenta a representação externa e beneficia a captação de recursos (Mizruchi \& Stearns, 1988).

Okhmatovskiy (2010) menciona que, em vários países, os governos além de regular as atividades empresariais, também se envolvem na governança corporativa das empresas, por meio da propriedade e/ou por laços no conselho de administração. Ademais, as empresas que estabelecem vínculos com membros do governo tendem a experimentar custos associados à tal participação no processo de governança corporativa. Deste modo, companhias com representante do governo no CA podem se beneficiar, mas também incorrer em alguns custos: o governo ter acesso às informações sensíveis da empresa e poder influenciar nas decisões estratégicas (Okhmatovskiy, 2010).

O intercâmbio entre conselheiros é um modo de se estabelecer laços no ambiente empresarial (interlocking), capaz de promover diversos benefícios às empresas (Bazerman \& Schoorman, 1983; Mizruchi \& Stearns, 1988; Schoorman, Bazermanm \& Atkin, 1981). A prática de interlocking permite o entrelaçamento de empresas pela relação de seus conselheiros, aumenta a representação externa e beneficia a captação de recursos (Mizruchi \& Stearns, 1988).

Os vínculos políticos por intermédio do interlocking facilitam o acesso das empresas as instituições de crédito (Johnson et al., 1996), mecanismos de extração de renda, proteção contra os concorrentes (Fan et al., 2007; Boubakri et al., 2012) e restrição de recursos às competidoras (Leuz \& Oberholzer-Gee, 2006). Além disso, estes vínculos favorecem o acesso as fontes financeiras e de informações, além de privilégios na disputa e preservação dos recursos, contribuindo nas decisões estratégicas e no desempenho das organizações (Claessens, Feijen \& Laeven, 2008; Faccio, 2006; Johnson, Daily \& Ellstrand, 1996). Wu, Wu, Zhou e Wu (2012) complementam que as empresas privadas com gerentes politicamente conectados gozam de benefícios fiscais mais elevados de suas contrapartes.

Deste modo, propõe-se a seguinte hipótese: $\mathrm{H}_{2}$ - Empresas com board interlocking pela expertise política aumentam a utilização de benefícios fiscais.

De acordo com Jensen e Meckling (1976), a Teoria da Agência é entendida como um contrato em que a parte principal se envolve com o agente. Se ambas as partes, agente e principal, agem com o propósito de maximizar suas utilidades pessoais, há um bom motivo para crer que o agente não terá ações voltadas para o interesse do principal.

Li, Meng, Wang e Zhou (2008) identificaram que a participação do partido político em empreendimentos privados da China tem um efeito positivo sobre o desempenho de suas empresas. No Brasil, Camilo et al. (2012) apontam que a conectividade com o ambiente político resulta em aumento de valor da firma, medidos pelo Q de Tobin e Market-to-book. Silva et al. (2018) aceitam a predição teórica de que o capitalismo de compadrio, pela conexão política, reduz o custo de capital e aumenta o desempenho das firmas pelo retorno sobre o patrimônio líquido. Contudo, Pinheiro, Luca e Vasconcelos (2016) Cruz e Parente (2018) indicam não haver diferença de desempenho na comparação das empresas com conexões políticas com aquelas sem qualquer conexão política.

Fan et al. (2007) destacam que a interferência política na gestão das empresas, pela qual se verifica uma ineficiência gerencial dos políticos, pode ser 
prejudicial ao desempenho das firmas. Boubakri et al. (2008) investigaram o impacto das conexões políticas em empresas recém-privatizadas. Pesquisaram 245 empresas com sede em 27 países em desenvolvimento e 14 países desenvolvidos, no período de 1980 a 2002. Concluíram que as empresas politicamente conectadas exibem um fraco desempenho contábil em comparação com suas contrapartes.

Adicionalmente, as empresas com vínculos diretos com o governo sofrerão custos significativos associados ao envolvimento de funcionários do governo no processo de governança corporativa, fator que prejudica a lucratividade das firmas (Okhmatovskiy, 2010). A partir deste contexto, formulou-se a seguinte hipótese: $\mathrm{H}_{3}$ - Empresas com vínculos políticos no conselho de administração apresentam menor geração de valor adicionado.

\section{BENEFÍCIOS FISCAIS E A GERAÇÃO DE VALOR ADICIONADO}

O benefício fiscal é um meio utilizado pelo Estado para concretizar as finalidades de ordem econômica, em prol do bem comum, disposto no Art. 170, da Constituição Federal. A concessão de benefícios fiscais é regulamentada por lei especial com dispositivos que desonerem a carga tributária pela isenção ou redução dos tributos (Ferreira, 1998). Os benefícios fiscais são renúncias de arrecadação que beneficiam as empresas, visando atrair investimentos para o território nacional, com o objetivo precípuo de fomentar setores produtivos (Lima \& Machado, 2018).

A concessão de benefícios fiscais se justifica quando concedidos de forma proporcional à defasagem na capacidade do governo local em prover bens públicos (Amaral Filho, 2009). As políticas governamentais são concebidas na forma de programa, com o objetivo de incrementar operações e atrair investimentos em regiões menos desenvolvidas (Taveira, 2009). Alguns governos conceberam incentivos fiscais por meio de regimes especiais de tributação, como meio de política industrial e de desenvolvimento regional (Maciel, 2010).

Ademais, com a publicação da LC 160/2017 e do Convênio Regulamentador 190/17 do Conselho Nacional de Política Fazendária (CONFAZ), deixou claro aos Estados a possibilidade da convalidação dos incentivos fiscais de ICMS que foram unilateralmente concedidos (Brasil, 2017). Com a alteração da Lei 12.973/14, ficou entendido que todo e qualquer benefício fiscal de ICMS concedido pelos Estados deve ser considerado como subvenções para investimento, ou seja, a transferência de recursos por meio de incentivos fiscais às empresas exige como contraprestação a aplicação dos valores para implantar ou expandir os empreendimentos econômicos (Brasil, 2014).

Sob o prisma das firmas, os benefícios fiscais devem ser revertidos em importantes incentivos financeiros, que se aplicados corretamente, podem aumentar a geração de riqueza adicionada na firma. Sendo assim, Kronbaver et al. (2011) concluem que as empresas que se utilizam de benefícios fiscais apresentam uma situação econômica financeira mais estável. Gonçalves, Nascimento e Wilbert (2016) estudaram o efeito dos benefícios fiscais na geração de riqueza, frente à elisão fiscal, concluindo que as empresas detentoras de benefícios fiscais agregaram maior valor adicionado. Lima e Machado (2018), 
destacam que há evidências empíricas que os benefícios fiscais influenciam a geração de riqueza pelas empresas.

Deste modo, tem-se a seguinte hipótese de pesquisa: $\mathrm{H}_{4}$ - Empresas com maior utilização de benefícios fiscais aumentam a geração de valor adicionado.

\section{PROCEDIMENTOS METODOLÓGICOS}

Em relação aos objetivos, a pesquisa caracteriza-se como explicativa, quanto aos procedimentos configura-se como documental e quanto à abordagem do problema é de cunho quantitativo. A população do estudo compreendeu as companhias abertas listadas $[\mathrm{B}]^{3}$ (bolsa de valores do Brasil), sendo excluídas as empresas do setor financeiro, aquelas que não apresentaram informações necessárias para a constituição das variáveis selecionadas e as empresas com valor adicionado negativo.

A partir destes critérios, a amostra da pesquisa ficou composta por 288 empresas. O período de análise compreendeu os anos de 2014 a 2017, totalizando 1.092 observações. Para esse recorte temporal, levou-se em consideração a LC n 160/2017 (Brasil, 2017), principalmente pela inclusão dos parágrafos $4^{\circ}$ e $5^{\circ}$ no art. 30 da Lei n. 12.973/2014 (Brasil, 2014), que passam a classificar todos os benefícios fiscais (sentido lato) de ICMS como subvenções para investimento a partir de 2014.

Para operacionalização do estudo, apresenta-se na Tabela 1 as variáveis e as fontes de coleta dos dados. Adicionalmente, são apresentados os autores que sustentam as variáveis necessárias ao objeto de estudo.

Tabela 1

Composição das variáveis do estudo

\begin{tabular}{|c|c|c|c|c|}
\hline Variáveis & \multicolumn{2}{|c|}{ Descrição } & Métrica & Autores de base \\
\hline Dependente & \multicolumn{2}{|c|}{$\begin{array}{l}\text { Geração de valor } \\
\text { adicionado (GVA) }\end{array}$} & $\begin{array}{l}\text { LN da geração de } \\
\text { valor adicionado } \\
\text { líquido na DVA }\end{array}$ & $\begin{array}{c}\text { Gonçalves et al. } \\
\text { (2016); Marostica } \\
\text { (2016). }\end{array}$ \\
\hline \multirow{3}{*}{ Independentes } & \multicolumn{2}{|c|}{ Benefícios fiscais (BFIS) } & $\begin{array}{l}\text { LN do valor das } \\
\text { reservas de incentivos } \\
\text { fiscais (PL) }\end{array}$ & $\begin{array}{l}\text { Luca e Lima (2007); } \\
\text { Lima e Machado } \\
\text { (2018) }\end{array}$ \\
\hline & \multicolumn{2}{|c|}{ Conexão Política (CP) } & $\begin{array}{c}\text { Proporção de } \\
\text { conselheiros de } \\
\text { administração que } \\
\text { são políticos ou ex- } \\
\text { políticos (ocupa ou } \\
\text { ocupou cargo } \\
\text { político) }\end{array}$ & $\begin{array}{c}\text { Chaney et al. } \\
\text { (2011); Boubakri et } \\
\text { al. (2012); Camilo } \\
\text { et al. (2012); Silva et } \\
\text { al. (2018) }\end{array}$ \\
\hline & $\begin{array}{l}\text { Board } \\
\text { Interlocking } \\
\text { pela } \\
\text { Expertise } \\
\text { Política } \\
\text { (BIEP) }\end{array}$ & $\begin{array}{l}\text { Board } \\
\text { Interlocking } \\
\text { (Laço } \\
\text { Direto) de } \\
\text { CA político } \\
\text { ou ex- } \\
\text { político }\end{array}$ & $\begin{array}{c}\text { Conselheiros de } \\
\text { administração com } \\
\text { expertise política e } \\
\text { compartilhamento } \\
\text { intrafirmas (direto), na } \\
\text { forma de quantidade } \\
\text { de laços } \\
\text { estabelecidos }\end{array}$ & $\begin{array}{l}\text { Boubakri et al. } \\
\text { (2012); Dal Magro e } \\
\text { Klann (2020) }\end{array}$ \\
\hline
\end{tabular}




\begin{tabular}{|c|c|c|c|}
\hline Variáveis & Descrição & Métrica & Autores de base \\
\hline \multirow{6}{*}{$\begin{array}{l}\text { Variáveis de } \\
\text { controle }\end{array}$} & Tamanho (TAM) & $\begin{array}{c}\text { Logaritmo natural do } \\
\text { ativo total da } \\
\text { empresa i no ano } †\end{array}$ & $\begin{array}{c}\text { Lapointe (2005); } \\
\text { Verriest e } \\
\text { Gaeremynck } \\
\text { (2009); Avallone e } \\
\text { Quagli (2015) }\end{array}$ \\
\hline & $\begin{array}{c}\text { Índice de } \\
\text { Competitividade (IHH) }\end{array}$ & $\begin{array}{c}\text { Somatório das } \\
\text { participações de } \\
\text { mercado de cada } \\
\text { empresa elevadas ao } \\
\text { quadrado } \\
\end{array}$ & $\begin{array}{c}\text { Sarmento e Nunes } \\
(2015)\end{array}$ \\
\hline & $\begin{array}{l}\text { Índice de Intangibilidade } \\
\text { (INT) }\end{array}$ & $\begin{array}{l}\text { (Ativo intangível da } \\
\text { empresa i no ano t) / } \\
\text { (Ativo total da } \\
\text { empresa i no ano t) }\end{array}$ & $\begin{array}{l}\text { Mazzioni, Carpes e } \\
\text { Lavarda (2014) }\end{array}$ \\
\hline & $\begin{array}{l}\text { Nível de Governança } \\
\text { Corporativa (NGC) }\end{array}$ & $\begin{array}{c}\text { Dummy igual a } 1 \text { para } \\
\text { empresas que } \\
\text { pertencem a algum } \\
\text { nível diferenciado de } \\
\text { governança } \\
\text { corporativa e } 0 \text { para } \\
\text { as demais }\end{array}$ & $\begin{array}{c}\text { Mazzioni, Carpes e } \\
\text { Lavarda (2014); } \\
\text { Marques et al. } \\
\text { (2015) }\end{array}$ \\
\hline & $\begin{array}{l}\text { Índice de Sustentabilidade } \\
\text { (ISE) }\end{array}$ & $\begin{array}{c}\text { Dummy igual a } 1 \text { para } \\
\text { empresas integrantes } \\
\text { da carteira ISE e } 0 \\
\text { para as demais }\end{array}$ & $\begin{array}{c}\text { Teixeira, Nossa e } \\
\text { Funchal (2011); } \\
\text { Mazzioni, Diel, Diel, } \\
\text { Kruger e Klann } \\
\text { (2014) }\end{array}$ \\
\hline & Utilidade Pública (UP) & $\begin{array}{c}\text { Dummy igual a } 1 \text { para } \\
\text { empresas que } \\
\text { pertencem ao setor } \\
\text { de utilidade pública e } \\
0 \text { para as demais }\end{array}$ & $\begin{array}{c}\text { Klöppel, } \\
\text { Schnorrenberger, } \\
\text { Lunkes (2013) }\end{array}$ \\
\hline
\end{tabular}

Fonte: elaborado pelos autores.

A Tabela 1 mostra as variáveis selecionadas na pesquisa em que a variável dependente foi composta pela "geração de valor adicionado" e as variáveis independentes pela "reserva de incentivos fiscais", "conexão política" e "board interlocking pela expertise política". Ademais, no modelo que verifica a influência dos vínculos políticos sobre os benefícios fiscais, utilizou-se como variável dependente a "reserva de incentivos fiscais".

Os dados da variável de geração de valor adicionado foram extraídos da Demonstração do Valor Adicionado (DVA), disponíveis no Formulário Demonstrações Financeiras Padronizadas (DFP), no sítio da [B] ${ }^{3}$. Para adequação do modelo foi transformada a variável (milhares de reais) em logaritmo natural (LN), similar ao adotado na pesquisa de Mazzioni, Carpes e Lavarda (2014). Para Cosenza e Vieira (2013), a DVA pode ser utilizada para mensurar e divulgar a riqueza gerada pela empresa, reduzir os conflitos de agência e assimetria de informações entre os acionistas e partes interessadas da empresa. Além disso, o demonstrativo pode ser utilizado como ferramenta gerencial e de avaliação do desempenho.

Os dados da variável Benefícios Fiscais foram coletados da base de dados da Economatica ${ }^{\circledR}$, a partir dos valores constantes na conta de reserva de investimento no Patrimônio Líquido das empresas. A variável Conexão Política foi 
definida pela razão de conselheiros com status de político ou ex-político sobre o número total de membros do conselho de administração.

A variável de board interlocking pela expertise política foi definida pela leitura do currículo de cada conselheiro da administração e aqueles que ocupam ou ocuparam cargo político na esfera municipal, estadual e federal foram caracterizados com expertise política (Faccio, 2006; Faccio, 2010; Boubakri et al., 2008; Chaney, Faccio \& Parsley, 2011). Pela identificação dos conselheiros de administração com expertise política foi possível a criação de uma matriz no Excel ${ }^{\circledR}$ para apontar se esses conselheiros ocupam cargos no conselho de administração de mais de uma empresa ao mesmo tempo. Para obtenção do indicador de ligação direta, utilizou-se a matriz no software UCINET ${ }^{\circledR}$, gerando o indicador de centralidade de grau pela análise das redes sociais.

Além disso, foram adicionadas as variáveis de controle: (i) quantitativas: tamanho da empresa, índice de competitividade e materialidade do intangível; (ii) categóricas: nível de governança corporativa, índice de sustentabilidade empresarial e utilidade pública. A escolha das variáveis de controle foi suportada em Lapointe (2005), que comprovou haver uma influência positiva do tamanho da empresa no valor adicionado. Mazzioni, Carpes e Lavarda (2014) identificaram que o grau de intangibilidade (MI) possui uma relação positiva com a geração do valor adicionado, indicando que as empresas mais intangíveis apresentam maior condição de gerar riqueza. O Nível de Governança Corporativa (NGC) foi testado no estudo de Marques, Guimarães e Peixoto (2015), que evidenciaram uma relação positiva entre o nível de governança corporativa e a geração de valor adicionado. Mazzioni, Diel, Diel, Kruger e Klann (2014) comprovaram que as empresas que integram o Índice de Sustentabilidade Empresarial (ISE) apresentam geração de valor adicionado superior. Klöppel, Schnorrenberger e Lunkes (2013) destacaram em seu estudo que a variável Utilidade Pública (UP) produz maiores índices de riqueza gerada pela atividade fim.

Para testar a influência de vínculos políticos e dos benefícios fiscais na geração do valor adicionado, foi utilizada a análise de dados em painel, com efeitos fixos de ano e setor, pelo teste de correção de White no software estatístico STATA ${ }^{\circledR}$.

\section{ANÁLISE E DISCUSSÃO DOS RESULTADOS}

Apresenta-se nesta seção a análise dos resultados. Inicialmente, tem-se a Tabela 2 com a estatística descritiva das variáveis quantitativas.

\section{Tabela 2}

Estatística descritiva das variáveis quantitativas

\begin{tabular}{l|r|r|r|r|r|r}
\multicolumn{1}{c|}{ Variáveis } & \multicolumn{1}{c|}{ N } & \multicolumn{1}{c|}{ Mínimo } & \multicolumn{1}{c|}{ Máximo } & \multicolumn{1}{c|}{ Média } & \multicolumn{1}{c}{ Mediana } & \multicolumn{1}{c}{ Desvio Padrão } \\
\hline GVA & 1092 & 0,0000 & 216.014 .000 & 3.169 .665 & 689.338 & 12.203 .528 \\
CP & 1092 & 0,0000 & 0,8750 & 0,0999 & 0,0000 & 0,1673 \\
BFIS & 1092 & 0,0000 & 7.388 .058 & 64.923 & 0,0000 & 387.609 \\
TAM & 1092 & 6.739 & 900.135 .000 & 12.884 .676 & 2.655 .158 & 56.146 .689 \\
BIEP & 1092 & 0,0000 & 14,0000 & 0,9112 & 0,0000 & 2,0174 \\
MI & 1092 & 0,0000 & 0,9145 & 0,1238 & 0,0103 & 0,2138 \\
IHH & 1092 & 0,0000 & 0,6558 & 0,0076 & 0,0001 & 0,0445 \\
\hline
\end{tabular}

Fonte: dados da pesquisa. 
Observa-se pelos valores médios e pelo desvio padrão, que o tamanho das empresas, o valor adicionado e os benefícios fiscais, apresentaram elevada dispersão. A materialidade do intangível representa 12,38\%, em média, dos ativos totais. Já o índice de competitividade, representa $0,76 \%$, em média, das participações de mercado de cada empresa. A conexão política representa 0,0999 da razão de conselheiros com status de político ou ex-político sobre o número total de membros do conselho de administração e o board interlocking pela expertise política representa uma centralidade de grau média de 0,9112.

A Tabela 3 apresenta a frequência das variáveis categóricas de controle:

Tabela 3

Frequência das variáveis categóricas de controle

\begin{tabular}{c|cc|cc|cc}
\hline \multirow{2}{*}{ Variáveis } & \multicolumn{2}{|c|}{ UP } & \multicolumn{2}{c|}{ NGC } & \multicolumn{2}{c}{ ISE } \\
& Frequência & $\%$ & Frequência & $\%$ & Frequência & $\%$ \\
\hline 0 & 843 & 77,20 & 536 & 49,08 & 977 & 89,47 \\
1 & 249 & 22,80 & 556 & 50,92 & 115 & 10,53 \\
\hline Total & 1092 & 100,0 & 1092 & 100,0 & 1092 & 100,0 \\
\hline
\end{tabular}

Fonte: dados da pesquisa.

Com relação às variáveis categóricas, observa-se que 22,80\% das empresas pertencem ao setor de utilidade pública (UP), 50,92\% possuem níveis diferenciados de governança corporativa (NGC) e 10,53\% participam do Índice de Sustentabilidade Empresarial (ISE).

Em seguida, buscou-se verificar a relação entre as variáveis, por meio do coeficiente de correlação de Pearson, com o propósito de identificar possíveis problemas de multicolinearidade nos dados. A presença de multicolinearidade não significa problemas do modelo, porém sua presença elevada pode gerar aumento no erro padrão (Gujarati, 2006). A Tabela 4 apresenta os resultados da correlação de Pearson entre as variáveis.

\section{Tabela 4}

Correlação de pearson entre as variáveis da pesquisa

\begin{tabular}{lcccccccccc}
\hline & GVA & CP & BFIS & TAM & BIEP & MI & NGC & ISE & IHH & UP \\
\hline GVA & 1 & $0,132^{* *}$ & $0,200^{* *}$ & $0,726^{* *}$ & $0,325^{* *}$ & $0,071^{*}$ & $0,376^{* *}$ & $0,349^{* *}$ & $0,260^{* *}$ & $0,224^{* *}$ \\
CP & 1 & $0,190^{* *}$ & $0,199^{* *}$ & $0,404^{* *}$ & 0,035 & $0,128^{* *}$ & $0,150^{* *}$ & 0,032 & $0,284^{* *}$ \\
BFIS & & & 1 & $0,153^{* *}$ & $0,244^{* *}$ & 0,027 & 0,036 & $0,082^{* *}$ & 0,017 & $0,188^{* *}$ \\
TAM & & & & 1 & $0,338^{* *}$ & $0,111^{* *}$ & $0,434^{* *}$ & $0,404^{* *}$ & $0,307^{* *}$ & $0,215^{* *}$ \\
BIEP & & & & & 1 & $0,091^{* *}$ & $0,198^{* *}$ & $0,277^{* *}$ & 0,055 & $0,276^{* *}$ \\
MI & & & & & 1 & $-0,098^{* *}$ & 0,022 & $-0,057$ & $0,174^{* *}$ \\
NGC & & & & & & 1 & $0,301^{* *}$ & $0,121^{* *}$ & $-0,113^{* *}$ \\
ISE & & & & & & & 1 & $0,075^{*}$ & $0,098^{* *}$ \\
IHH & & & & & & & & 1 & $-0,085^{* *}$ \\
UP & & & & & & & & & 1 \\
\hline
\end{tabular}

**A correlação é significativa no nível 1\%. *A correlação é significativa no nível 5\%.

Fonte: dados da pesquisa.

Conforme observado na Tabela 4, constata-se uma relação positiva entre a geração de valor adicionado e os benefícios fiscais, a conexão política e o board interlocking pela expertise política e com as variáveis de controle: tamanho (TAM), materialidade do intangível (MI), nível de governança corporativa (NGC), 
índice de sustentabilidade empresarial (ISE), índice de competitividade (IHH) e utilidade pública (UP).

Constatou-se que as variáveis independentes apresentaram significância entre si, com coeficientes relativamente fracos ou moderados. A única exceção foi a relação entre tamanho da empresa e geração de valor adicionado, com relação forte, contudo, não foram verificados problemas de multicolinearidade no uso do modelo.

A Tabela 5 mostra os resultados dos modelos que verificam a influência dos vínculos políticos (conexão política e board interlocking pela expertise política) na obtenção dos benefícios fiscais.

\section{Tabela 5}

Influência de vínculos políticos (conexão política e board interlocking pela expertise política) na obtenção dos benefícios fiscais

\begin{tabular}{|c|c|c|c|c|c|c|}
\hline \multirow[t]{2}{*}{ Variáveis } & \multicolumn{2}{|c|}{$\begin{array}{c}\text { Modelo } 1 \\
\text { BFIS }\end{array}$} & \multicolumn{2}{|c|}{$\begin{array}{c}\text { Modelo } 2 \\
\text { BFIS }\end{array}$} & \multicolumn{2}{|c|}{$\begin{array}{c}\text { Modelo } 3 \\
\text { BFIS }\end{array}$} \\
\hline & Coef. & Sig. & Coef. & Sig. & Coef. & Sig. \\
\hline$C P$ & 2,46857 & $0,028^{*}$ & 1,985762 & 0,067 & 2,565808 & $0,020 *$ \\
\hline BIEP & 0,3510292 & $0,000 *$ & 0,320631 & $0,000 *$ & 0,3871996 & $0,000 *$ \\
\hline TAM & 0,2235988 & $0,003^{*}$ & 0,1657884 & $0,038^{*}$ & - & - \\
\hline MI & $-0,2056887$ & 0,664 & $-0,3727015$ & 0,414 & - & - \\
\hline NGC & $-0,4317303$ & 0,127 & $-0,2241917$ & 0,430 & - & - \\
\hline ISE & $-0,1079856$ & 0,829 & $-0,1125287$ & 0,822 & - & - \\
\hline IHH & $-1,810461$ & 0,392 & $-0,5129044$ & 0,818 & - & - \\
\hline UP & - & - & 0,9507839 & $0,007^{*}$ & - & - \\
\hline $\mathbf{R}^{2}$ & \multirow{3}{*}{\multicolumn{2}{|c|}{$\begin{array}{c}0,0769 \\
1,055 \text { a } 1,627 \\
0,000^{*}\end{array}$}} & \multirow{3}{*}{\multicolumn{2}{|c|}{$\begin{array}{c}0,0850 \\
1,065 \text { a } 1,719 \\
0,000^{*}\end{array}$}} & \multirow{3}{*}{\multicolumn{2}{|c|}{$\begin{array}{c}0,0690 \\
1,195 \\
0,000^{*}\end{array}$}} \\
\hline VIF & & & & & & \\
\hline Sig. ANOVA & & & & & & \\
\hline
\end{tabular}

*Significância ao nível de 5\%; **Significância ao nível de $10 \%$.

Fonte: dados da pesquisa.

No modelo 1 foram consideradas as variáveis de conexão política em conjunto com as variáveis de controle; no modelo 2 foi adicionada a variável de setor àquelas utilizadas no modelo 1; no modelo 3 foram consideradas somente as variáveis de conexão política. Nos três modelos a variável dependente representa os benefícios fiscais.

Verifica-se na Tabela 5 que a conexão política apresentou significância com os benefícios fiscais em dois modelos analisados (1 e 3), ou seja, empresas conectadas aos políticos, por intermédio de conselheiros de administração tendem a aumentar o uso dos benefícios fiscais gerando maiores incentivos para expansão e crescimento.

Além disso, o vínculo político relacionado ao board interlocking pela expertise política demonstrou influência sobre o aumento no uso dos benefícios fiscais, ou seja, as empresas que formam redes de ligações diretas pelo compartilhamento de conselheiros de administração com expertise política (políticos ou ex-políticos) tendem a transmitir informações que favorecem as partes inter-relacionados na utilização dos benefícios fiscais concedidos pelos entes públicos. A maior propensão ao acesso de benefícios fiscais via expertise política foi confirmada nos três modelos analisados (1, 2 e 3). 
Verifica-se que a variável tamanho (TAM) apresentou significância estatística para explicar os benefícios fiscais (modelos 1 e 2), ou seja, as grandes empresas tendem a receber mais incentivos fiscais. Este achado indica que as empresas maiores possuem maior expertise e/ou acesso facilitado aos benefícios fiscais do governo.

Outra variável que demonstrou influenciar o aumento no uso dos incentivos fiscais foi a que representa as empresas de utilidade pública (modelo 2), ou seja, as empresas do segmento público recebem mais benefícios fiscais, tendo em vista que seus objetivos estão mais alinhados com os objetivos do Governo de implementar projetos de investimento.

As variáveis de controle materialidade do intangível, nível de governança corporativa, índice de sustentabilidade empresarial e índice de competitividade não se mostraram significativas em nenhum dos dois modelos apresentados para explicar os incentivos fiscais, inviabilizando considerações mais detalhadas sobre sua influência.

Desse modo, a partir dos resultados do modelo de regressão linear múltipla, a hipótese $H_{1}$ (empresas com presença de políticos no conselho de administração estão mais propensas aos benefícios fiscais), não foi refutada. De modo semelhante, a hipótese $\mathrm{H}_{2}$ (empresas com board interlocking pela expertise política aumentam a utilização de benefícios fiscais) também não foi refutada.

Os resultados corroboram a Teoria da Dependência de Recursos (Aldrich \& Pffefer, 1976), quando evidenciado que empresas com a presença de políticos no conselho de administração ou que possuem vínculos políticos aumentam a utilização dos incentivos fiscais, o que também é destacado por Baysinger (1984) e Pfeffer \& Salancik (2003), em que as empresas por meio de conexões políticas buscam o governo para aproveitar os benefícios fiscais (Hillman, 2005).

Ademais, os achados contribuem com os estudos de Wu et al. (2012), tendo em vista que as empresas com vínculos políticos apresentaram maiores benefícios fiscais e as empresas conectadas via board interlocking pela expertise política são capazes de conseguir diversos benefícios (Bazerman \& Schoorman, 1983; Mizruchi \& Stearns, 1988; Schoorman, Bazermanm \& Atkin, 1981), são favorecidas pelo acesso às informações financeiras e privilégios na obtenção de recursos (Bazerman \& Schoorman, 1983; Mizruchi \& Stearns, 1988; Schoorman, Bazermanm \& Atkin, 1981).

A Tabela 6 apresenta os resultados dos modelos que analisam a influência da conexão política e dos benefícios fiscais na geração do valor adicionado das companhias abertas listadas na $[\mathrm{B}]^{3}$. 


\section{Tabela 6}

Influência dos benefícios fiscais e da conexão política na geração de valor adicionado

\begin{tabular}{|c|c|c|c|c|c|c|}
\hline \multirow[t]{2}{*}{ Variáveis } & \multicolumn{2}{|c|}{$\begin{array}{c}\text { Modelo } 1 \\
\text { GVA }\end{array}$} & \multicolumn{2}{|c|}{$\begin{array}{c}\text { Modelo } 2 \\
\text { GVA }\end{array}$} & \multicolumn{2}{|c|}{$\begin{array}{c}\text { Modelo } 3 \\
\text { GVA }\end{array}$} \\
\hline & Coef. & Sig. & Coef. & Sig. & Coef. & Sig. \\
\hline BFIS & 0,0497975 & $0,000 *$ & 0,0485957 & $0,000^{*}$ & $-0,0340935$ & 0,615 \\
\hline$C P$ & $-0,8037935$ & $0,005^{*}$ & $-0,8288668$ & $0,016^{*}$ & $-0,8036832$ & $0,005^{*}$ \\
\hline IHH & 3,111535 & $0,000 *$ & 3,109263 & $0,000^{*}$ & 3,06484 & $0,000 *$ \\
\hline UP & 0,545846 & $0,000^{*}$ & 0,5447792 & $0,000^{*}$ & 0,5481523 & $0,000 *$ \\
\hline TAM & 0,7373892 & $0,000 *$ & 0,7378346 & $0,000 *$ & 0,7321716 & $0,000^{*}$ \\
\hline MI & $-0,0442347$ & 0,892 & $-0,0465198$ & 0,886 & $-0,04232286$ & 0,897 \\
\hline NGC & 0,4379089 & $0,004^{*}$ & 0,435904 & $0,004^{*}$ & 0,4443741 & $0,004^{*}$ \\
\hline ISE & 0,4113014 & $0,000 *$ & 0,4134581 & $0,000 *$ & 0,399082 & $0,000 *$ \\
\hline BFIS*CP & - & - & 0,0075088 & 0,816 & - & - \\
\hline BFIS*TAM & - & - & - & - & 0,005415 & 0,231 \\
\hline $\mathbf{R}^{2}$ & \multicolumn{2}{|c|}{0,5545} & \multicolumn{2}{|c|}{0,5545} & \multirow{3}{*}{\multicolumn{2}{|c|}{$\begin{array}{c}0,5547 \\
1,063 \text { a } 105,422 \\
0,000^{*}\end{array}$}} \\
\hline VIF & \multirow{2}{*}{\multicolumn{2}{|c|}{1,063 a 1,695}} & \multirow{2}{*}{\multicolumn{2}{|c|}{$\begin{array}{c}1,068 \text { a } 2,046 \\
0,000^{*}\end{array}$}} & & \\
\hline Sig. ANOVA & & & & & & \\
\hline
\end{tabular}

*Significância ao nível de 5\%; **Significância ao nível de $10 \%$.

Fonte: dados da pesquisa.

No modelo 1 foram consideradas as variáveis de conexão política e benefícios fiscais em conjunto com as variáveis de controle. No modelo 2 foi adicionada a variável moderadora das empresas que possuem conexão política e benefícios fiscais de forma concomitante, àquelas utilizadas no modelo 1 . No modelo 2 foi adicionada a variável moderadora tamanho e benefícios fiscais de forma concomitante, àquelas utilizadas no modelo 1. Nos três modelos a variável dependente é a geração de valor adicionado.

Com relação à Tabela 6, verifica-se que os benefícios fiscais apresentaram significância estatística para explicar a geração de valor adicionado em dois modelos analisados ( 1 e 2). Os resultados apontam que as empresas ao acessar mais incentivos fiscais tendem a gerar volume maior de riquezas, consistente com os achados de Lima e Machado (2018).

Por sua vez, a conexão política influenciou de forma negativa a geração de valor adicionado nos três modelos analisados (1, 2 e 3). Visualiza-se que empresas com menores vínculos políticos tendem a gerar valor adicionado mais elevado, ou seja, possuem um desempenho superior daquelas conectadas politicamente. Os resultados divergem do estudo de Camilo et al. (2012), pois evidenciaram relação significativa entre a dependência de recursos do governo e a intensidade de conexões políticas.

Verificou-se que o índice de competitividade também apresentou significância nos três modelos analisados (1, 2 e 3), ou seja, quanto mais competitivo o setor, maior a geração do valor adicionado. Além disso, a variável de Utilidade Pública apresentou significância estatística para explicar a geração de valor adicionado nos três modelos apresentados, corroborando os achados prévios de Klöppel, Schnorrenberger e Lunkes (2013).

Verifica-se no estudo que o tamanho da empresa é uma variável que apresentou significância com a geração de riquezas (modelos 1, 2 e 3). Em geral, as grandes empresas têm a capacidade de melhorar seu desempenho, proporcionando geração de valor adicionado, confirmando os argumentos de Lapointe (2005). No que diz respeito a materialidade do intangível, a variável 
apresentou relação negativa e não significativa, diferente do estudo de Mazzioni, Carpes e Lavarda (2014).

A análise de resultados também demonstra significância para a variável de controle nível de governança corporativa em explicar a geração de valor adicionado (modelos 1, 2 e 3). Ou seja, empresas que pertencem a algum nível diferenciado de governança corporativa da $[B]^{3}$, que se comprometem a adotar práticas mais consistentes de governança corporativa possuem desempenhos superiores na geração de valor adicionado.

Verificou-se que empresas pertencentes ao Índice de Sustentabilidade Empresarial demonstraram maior capacidade na geração de valor adicionado, cujo resultado é coerente com o estudo de Mazzioni et al. (2014). Pode-se inferir que ao criar um ambiente de investimento compatível com as demandas de desenvolvimento sustentável da sociedade contemporânea e estimular a responsabilidade ética, as empresas estão mais propensas a gerar valor adicionado, confirmado em todos os modelos analisados (1, 2 e 3).

A variável moderadora BFISxCP não se mostrou significativa, indicando que empresas conectadas politicamente e que também possuem incentivos fiscais, não influenciaram na geração de valor adicionado. A variável moderadora BFISXTAM também não se mostrou significativa para explicar a produção de riquezas, indicando que as empresas maiores e que recebem benefícios fiscais concomitantemente, não apresentaram maior geração de valor adicionado em relação às suas contrapartes.

Assim, a partir dos modelos de regressão utilizados, a hipótese $\mathrm{H}_{3}$ (empresas com vínculos políticos no conselho de administração apresentam menor geração de valor adicionado) e a hipótese $\mathrm{H}_{4}$ (empresas com maior utilização de benefícios fiscais aumentam a geração de valor adicionado), foram aceitas.

Os resultados confirmam o pressuposto da Teoria da Agência, de que o agente atua com o intuito de maximizar sua utilidade pessoal, em detrimento da empresa (Jensen \& Meckling, 1976), como consequência, as empresas apresentaram menor geração de valor adicionado, diminuindo o desempenho das empresas. Estão alinhados, também, com a Teoria da Dependência de Recursos, ao considerar que os incentivos fiscais auxiliam as empresas na constituição de reserva de recursos e no incremento da geração de riquezas (Aldrich \& Pffefer, 1976), conforme já destacado por Afonso et al. (2014).

Esses resultados são condizentes com Fan et al. (2007), Wu et al. (2012) e Boubakri et al. (2008), os quais indicaram que vínculos políticos são prejudiciais para o desempenho das empresas. Entretanto, os resultados não corroboram o estudo de Li et al. (2008), quando em seus achados destacaram que a participação de políticos em empresas tem um efeito positivo sobre o desempenho das firmas.

Os achados no presente estudo confirmam os resultados de Gonçalves, Nascimento e Wilbert (2016) e Lima e Machado (2018), ao indicar que empresas com maior utilização de incentivos fiscais aumentam a geração de valor adicionado, como consequência, o desempenho das firmas.

De forma sintética, a Tabela 7 evidencia os resultados das hipóteses propostas para o estudo. 


\section{Tabela 7}

Resumo dos resultados das hipóteses de pesquisa

\begin{tabular}{l|l}
\hline \multicolumn{1}{|c|}{ Hipóteses } & Resultados \\
\hline $\mathrm{H}_{1}-$ Empresas com maior presença de políticos no conselho de & Corroborada \\
administração estão mais propensas a se utilizarem de benefícios fiscais. & \\
$\mathrm{H}_{2}-$ Empresas com board interlocking pela expertise política aumentam a & Corroborada \\
utilização de benefícios fiscais. & \\
$\mathrm{H}_{3}-$ Empresas com vínculos políticos no conselho de administração & Corroborada \\
apresentam menor geração de valor adicionado. & Corroborada \\
$\mathrm{H}_{4}-$ Empresas com maior utilização de benefícios fiscais aumentam a \\
geração de valor adicionado.
\end{tabular}

Fonte: dados da pesquisa.

Com base nos resultados desta pesquisa evidenciou-se que as empresas brasileiras de capital aberto, listadas na $[B]^{3}$ entre os anos de 2014 a 2017, que compõem a amostra deste estudo, quando possuem presença de políticos no conselho de administração estão mais propensas ao acesso dos benefícios fiscais. Ademais, empresas conectadas politicamente apresentam menor geração de valor adicionado, enquanto as que estão propensas aos benefícios fiscais apresentam maior geração de valor adicionado, corroborando as hipóteses da pesquisa.

Os resultados confirmam as inquietações de Afonso et al. (2014), em que os benefícios fiscais devem proporcionar valor adicionado para as organizações. Nesse sentido, de acordo com a Teoria da Dependência de Recursos, os benefícios fiscais auxiliam as empresas na reserva de recursos, que quando reaplicados em investimentos retornam em geração de valor adicionado.

Por outro lado, os resultados indicam que os vínculos políticos aumentam os benefícios fiscais, mas reduzem o valor adicionado das organizações, gerando assim possíveis conflitos de agência, quando os políticos se vinculam às empresas privadas. Os políticos auxiliam as empresas na obtenção de benefícios fiscais, fazendo com que criem dependência para a obtenção de recursos, contudo geram conflitos de agência com os demais investidores, ao prejudicar a geração de valor adicionado em detrimento dos seus interesses particulares.

\section{CONSIDERAÇÕES FINAIS}

A influência da conexão política, tanto com políticos no conselho de administração ou executivos que estão na vida pública, pode ocasionar maior obtenção de benefícios fiscais. Entretanto, é importante verificar o objetivo na concessão dos incentivos fiscais para as empresas, pois estas devem reverter os benefícios auferidos em geração de riquezas à economia do país.

Os resultados relevaram que as empresas com conexão política e board interlocking (vínculos políticos) estão propensas ao uso de benefícios fiscais. Sugere-se que isso ocorre porque as empresas privadas utilizam-se das conexões políticas como um caminho para obter recursos que auxiliam as empresas na geração de valor adicionado, corroborando com os argumentos da Teoria da Dependência de Recursos.

Ademais, a presença de políticos no conselho de administração faz com que as empresas tenham menor eficiência no uso dos benefícios fiscais, gerando 
menor valor adicionado. Em consonância com a Teoria da Agência, quando existem conflitos entre os agentes e o principal, aqueles expropriam os proprietários, maximizando seus interesses pessoais em detrimento do desempenho das empresas. Conclui-se que a presença concomitante de vínculos políticos e uso dos benefícios fiscais não provocam o efeito desejado na geração de valor adicionado pelas empresas e, portanto, ampliam-se os conflitos de agência. Esse resultado representa divergência (conflito) no interesse dos acionistas, tendo em vista que a menor geração de valor adicionado representa, inclusive, menor retorno para remuneração do capital próprio.

As empresas com maior utilização de benefícios fiscais aumentam a geração de valor adicionado. Sendo assim, as empresas que não possuem conexão política ou políticos no conselho de administração utilizam as reservas de benefícios fiscais na expansão e desenvolvimento da empresa, proporcionando aumento na geração de valor adicionado.

Verificou-se que as grandes empresas são capazes de gerar mais riquezas e são as que mais utilizam-se dos benefícios fiscais. Aquelas classificadas com nível diferenciado de governança corporativa, as empresas do setor de utilidade pública, as mais competitivas no mercado e as que integram o Índice de Sustentabilidade Empresarial apresentaram maior geração de valor adicionado.

Entretanto, quando analisadas em conjunto as empresas que possuem vínculos políticos e benefícios fiscais (BFISxCP), as empresas maiores e que possuem benefícios fiscais (BFISXTAM), tais características não influenciaram a geração de valor adicionado. Esse achado comprova que empresas com vínculos políticos e que utilizam benefícios fiscais, concomitantemente, não conseguem ter o mesmo desempenho na geração de valor adicionado em comparação com as empresas que usufruem dos benefícios fiscais e não possuem vínculos com políticos.

No entanto, quando analisado a influência da conexão política nos benefícios fiscais, os resultados apontaram uma relação significativa da conexão política, dos laços diretos, do tamanho da empresa e empresas do setor de utilidade pública. Esses resultados indicam que as empresas com vínculos políticos recebem mais benefícios fiscais e são, com maior frequência, empresas de utilidade pública.

Verifica-se que este estudo fornece insights importantes para o entendimento dos temas abordados. Mais precisamente, para pesquisadores que buscam examinar a geração do valor adicionado influenciado pelos incentivos fiscais e pelas conexões políticas. Para os governos, os resultados evidenciam uma forma de avaliar se os benefícios concedidos às empresas que tem por objetivo gerar valor adicionado para promover o desenvolvimento das regiões por meio de investimentos, estão de fato desempenhando esse papel.

O estudo contribui na evidenciação aos usuários da informação (internos e externos), principalmente aos gestores e o governo que devem estar atentos quanto aos efeitos negativos das conexões políticas na geração de valor adicionado, mesmo quando as empresas se utilizam dos incentivos fiscais, os quais deveriam melhorar a geração de riquezas. Desse modo, para que as empresas atinjam uma geração de valor adicionado compatível com os objetivos do governo na oferta de benefícios fiscais (retorno para a sociedade e outras partes), é necessário o adequado investimento dos recursos pelas empresas e o 
monitoramento dos interesses particulares dos indivíduos com vínculos políticos, que estão no conselho de administração e/ou são acionistas com participação relevante no capital.

\section{REFERÊNCIAS}

Afonso, J. R. R., Silveira, R. F., Carvalho, C. M. S., Klintowitz, D., \& Azevedo, F. D. (2014). A renúncia tributária do ICMS no Brasil. Banco Interamericano de Desenvolvimento.

Albuquerque, T. S. (2016). Board Interlocking no Brasil - Aspectos societários da participação de conselheiros em múltiplas empresas. Leya.

Aldrich, H. E., \& Pfeffer, J. (1976). Environments of organizations. Annual Review of Sociology, 2(1), 79-105. doi:10.1146/annurev.so.02.080176.000455

Amaral Filho, J. D. (2009). A endogeneização no desenvolvimento econômico regional e local. Planejamento e Políticas Públicas, (23), 261-283.

Assunção, M. C. (2011). Incentivos Fiscais e Desenvolvimento Econômico: a função das normas tributárias indutoras em tempos de crise. Revista da PGFN, 1(1), 99-121.

Bianchet, T. D. S., Zanin, A., Mazzioni, S., \& Moura, G. D. (2019). Diferenças no valor adicionado em empresas familiares e não familiares listadas na BM\&FBovespa. Enfoque Reflexão Contábil, 38(1), 85-104. doi: 10.4025/enfoque.v38i1.39681

Cruz, P. Y. G., \& Parente, P. H. N. (2018). Desempenho e conexão política no Brasil: uma análise a partir das eleições de 2014. Navus: Revista de Gestão e Tecnologia, 8(3), 8-22. doi:10.22279/navus.2018.v8n3.p08-22.662

Bandeira-de-Mello, R., \& Marcon, R. (2011). The value of business group affiliation for political connections: preferential lending in Brazil. XXème Conférence de I'AIMS (Association Internationale de Managment Strategique).

Battiston, S., Weisbuch, G., \& Bonabeau, E. (2003). Decision spread in the corporate board network. Advances in Complex Systems, 6(04), 631-644. Doi:10.1 142/S021952903001109

Baysinger, B. D. (1984). Domain maintenance as an objective of business political activity: An expanded typology. Academy of Management Review, 9(2), 248258. doi:10.2307/258438

Bazerman, M. H., \& Schoorman, F. D. (1983). A limited rationality model of interlocking directorates. Academy of Management Review, 8(2), 206-217. doi:10.5465/amr.1983.4284723 
Borini, F. M., \& Lucchesi, E. P. (2007). Gestão das empresas multinacionais e os conflitos de agência. Revista Eletrônica de Ciência Administrativa, 6(2), 1-10. doi:10.21529/recadm.20070602007

Boubakri, N., Cosset, J. C., \& Saffar, W. (2008). Political connections of newly privatized firms. Journal of Corporate Finance, 14(5), 654-673. doi:10.1016/j.jcorpfin.2008.08.003

Boubakri, N., Guedhami, O., Mishra, D., \& Saffar, W. (2012). Political connections and the cost of equity capital. Journal of Corporate Finance, 18(3), 541-559. doi:10.1016/j.jcorpfin.2012.02.005

Brasil. Lei Complementar $\mathrm{n}^{\circ}$ 160, de 7 de agosto de 2017. Diário Oficial [da] República Federativa do Brasil, Poder Executivo, Brasília, DF, 22 nov. 2017.

Brasil. Lei n 12.973, de 13 de maio de 2014. Diário Oficial [da] República Federativa do Brasil, Poder Executivo, Brasília, DF, 13 maio. 2014.

Camilo, S. P. O., Marcon, R., \& Bandeira-de-Mello, R. (2012). Conexões políticas e desempenho: um estudo das firmas listadas na BM\&FBovespa. RAC - Revista de Administração Contemporânea, 16(6), 806-826. doi:10.1590/s141565552012000600003

Chaney, P. K., Faccio, M., \& Parsley, D. (2011). The quality of accounting information in politically connected firms. Journal of Accounting and Economics, 51 (1-2), 58-76. doi:10.1016/j.jacceco.2010.07.003

Chen, T. Y., GU, Z., Kubota, K., \& Takehara, H. (2015). Accrual-based and real activities based earnings management behavior of family firms in Japan. The Japanese Accounting Review, 5, 21-47. doi:10.11640/tjar.5.2015.02

Claessens, S., Feijen, E., \& Laeven, L. (2008). Political connections and preferential access to finance: The role of campaign contributions. Journal of Financial Economics, 88(3), 554-580. doi:10.1016/j.jfineco.2006.11.003

Cosenza, J. P., \& Vieira, S. M. (2013). Utilidade da demonstração do valor adicionado na evidenciação do valor econômico das empresas. Registro Contábil, 4(1), 127-140.

Cunha, J. V. A. D., Ribeiro, M. D. S., \& Santos, A. D. (2005). A demonstração do valor adicionado como instrumento de mensuração da distribuição da riqueza. Revista Contabilidade \& Finanças, 16(37), 7-23. doi: 10.1590/S151970772005000100001

Dal Magro, C. B. (2017). Efeito moderador de expertises de membros do board interlocking em incentivos para as práticas de gerenciamento de resultados mediante atividades reais. Tese de Doutorado em Ciências Contábeis e Administração, Universidade Regional de Blumenau - FURB, Blumenau, SC, Brasil. 
Dal Magro, C. B., \& Carlos Klann, R. (2020). A new look at board interlocking: evidence from corporate social networks. RAP: Revista Brasileira de Administração Pública, 54(1), 121-141. doi: 10.1590/0034-761220180293x

Dulci, O. S. (2002). Guerra fiscal, desenvolvimento desigual e relações federativas no Brasil. Revista de Sociologia e Política, 18, 95-107. doi:10.1590/s010444782002000100007

Faccio, M. (2006). Politically connected firms. American Economic Review, 96(1), 369-386. doi:10.1257/000282806776157704

Fan, J. P., Guan, F., Li, Z., \& Yang, Y. G. (2014). Relationship networks and earnings informativeness: Evidence from corruption cases. Journal of Business Finance \& Accounting, $41(7-8), 831-866$. doi:10.1111/jbfa.12078

Fan, J. P., Wong, T. J., \& Zhang, T. (2007). Politically connected CEOs, corporate governance, and Post-IPO performance of China's newly partially privatized firms. Journal of Financial Economics, 84(2), 330-357. doi:10.1016/j.jfineco.2006.03.008

Ferreira, S. D. A. (1998). O incentivo fiscal como instituto de Direito Econômico. Revista de Direito Administrativo, 211, 31-46. doi:10.12660/rda.v211.1998.47124

Fisman, R. (2001). Estimating the value of political connections. American Economic Review, 91(4), 1095-1102. doi:10.1257/aer.91.4.1095

Godoy, P. D., \& Marcon, R. (2008). Teoria da agência e os conflitos organizacionais: a influência das transferências e das promoções nos custos de agência em uma instituição bancária. Revista de Administração Mackenzie (Mackenzie Management Review), 7(4), 169-210. doi:10.1590/1678-69712006/administracao.v7n4p168-210

Goldman, E., Rocholl, J., \& So, J. (2008). Do politically connected boards affect firm value? The Review of Financial Studies, 22(6), 2331-2360. doi:10.1093/rfs/hhn088

Gonçalves, R. D. S., Nascimento, G. G. D., \& Wilbert, M. D. (2016). Os efeitos da subvenção governamental frente à elisão fiscal e a geração de riqueza. Revista Catarinense da Ciência Contábil, 15(45), 33-48. doi:10.16930/2237-7662/rccc.v15n45p34-48

Gujarati, D. N. (2006). Econometria Básica. Rio de Janeiro: Elsevier.

Hillman, A. J. (2005). Politicians on the board of directors: do connections affect the bottom line? Journal of Management, 31 (3), 464-481. doi:10.1177/0149206304272187 
Hillman, A. J., \& Hitt, M. A. (1999). Corporate political strategy formulation: A model of approach, participation, and strategy decisions. Academy of Management Review, 24(4), 825-842. doi:10.5465/amr.1999.2553256

Infante, L., \& Piazza, M. (2014). Political connections and preferential lending at local level: Some evidence from the Italian credit market. Journal of Corporate Finance, 29, 246-262. doi:10.1016/j.jcorpfin.2014.06.003

Jensen, M. C., \& Meckling, W. H. (1976). Theory of the firm: Managerial behavior, agency costs and ownership structure. Journal of Financial Economics, 3(4), 305-360. doi:10.1016/0304-405x(76)90026-x

Johnson, J. L., Daily, C. M., \& Ellstrand, A. E. (1996). Boards of directors: A review and research agenda. Journal of Management, 22(3), 409-438. doi:10.1177/014920639602200303

Khwaja, A. I., \& Mian, A. (2005). Do lenders favor politically connected firms? Rent provision in an emerging financial market. The Quarterly Journal of Economics, 120(4), 1371-1411. doi:10.1162/003355305775097524

Klöppel, F., Schnorrenberger, D., \& Lunkes, R. J. (2013). Análise da geração e distribuição da riqueza originada pelas empresas que compõem o lbovespa por meio da DVA. Revista Catarinense da Ciência Contábil, 12(34), 23-39. doi:10.16930/2237 7662/rccc.v12n34p23-39

Kronbaver, C. A., Schneider, L. C., Lumbieri, L., Pereira, F. A., \& Zani, J. (2011). Relação custo-benefício dos incentivos fiscais: Um estudo baseado na DVA de empresas calçadistas incentivadas. ABCustos, 6(3), 1-23. doi: 10.47179/abcustos.v6i3.202

Leuz, C., \& Oberholzer-Gee, F. (2006). Political relationships, global financing, and corporate transparency: Evidence from Indonesia. Journal of Financial Economics, 81 (2), 41 1-439. doi:10.1016/j.jfineco.2005.06.006

Li, H., Meng, L., Wang, Q., \& Zhou, L. A. (2008). Political connections, financing and firm performance: Evidence from Chinese private firms. Journal of Development Economics, 87(2), 283-299. doi:10.1016/j.jdeveco.2007.03.001

Lima, L. V. A., \& Machado, M. R. (2018). Incentivos fiscais e sua influência no valor adicionado produzido pelas empresas. Anais do Congresso Anpcont, João Pessoa, PB, Brasil, 12 Recuperado de http://www.anpcont.org.br/pdf/2018_CUE75.pdf.

Luca, M. M. M., \& Lima, V. F. L. (2007). Efeito dos incentivos fiscais no patrimônio das entidades beneficiárias do programa FDI, do governo do estado do Ceará. Contextus -Revista Contemporânea de Economia e Gestão, 5(1), 2944. doi:10.19094/contextus.v5i1.32082 
Maciel, M. S. (2010). Política de incentivos fiscais: quem recebe isenção por setores e regiões do país. Consultoria Legislativa. Câmara dos Deputados. Estudo Março/2010. Disponível em: http://bit.ly/18i3eDl.

Marostica, J. (2016). Custo-benefício dos incentivos fiscais e indicadores de desempenho das empresas calçadistas listadas na BM\&FBovespa (Dissertação de mestrado) - Universidade Federal de Santa Catarina, Florianópolis, SC, Brasil.

Marques, T. D. A., Guimarães, T. M., \& Peixoto, F. M. (2015). A concentração acionária no Brasil: análise dos impactos no desempenho, valor e risco das empresas. Revista de Administração Mackenzie (Mackenzie Management Review), 16(4), 100-133.

doi:10.1590/167869712015/administracao.v16n4p100-133

Matkin, D. S. (2010). Designing accountable and effective economic development tax Incentives: A study of corporate tax credits in Kansas. Public Performance \& Management Review, 34(2), 166-188. doi:10.2753/pmr15309576340202

Mazzioni, S., Silva Carpes, A. M. D. S., \& Facin Lavarda, C. E. F. (2014). A relação entre o grau de intangibilidade e a geração de valor adicionado em empresas brasileiras de capital aberto. Enfoque: Reflexão Contábil, 33(2), 7186. doi:10.4025/enfoque.v33i2.22298

Mazzioni, S., Diel, F. J., Diel, E. H., Kruger, S. D., \& Klann, R. C. (2014). Análise dos indicadores de valor adicionado das empresas participantes do Índice de Sustentabilidade Empresarial (ISE) comparados às demais empresas listadas na BM\&FBOVESPA. Contextus - Revista Contemporânea de Economia e Gestão, 11 (2), 159-180. doi:10.19094/contextus.v11i2.32167

Mizruchi, M. S., \& Stearns, L. B. (1988). A longitudinal study of the formation of interlocking directorates. Administrative Science Quarterly, 33(2), 194-210. doi:10.2307/2393055

Okhmatovskiy, I. (2010). Performance implications of ties to the government and SOEs: A political embeddedness perspective. Journal of Management Studies, 47(6), 1020-1047. doi:10.1111/j.1467-6486.2009.00881.x

Oliveira, L. G. S. M., Cunha, J. V. A., Nascimento, S. A., \& Avelino, B. C. (2014). Análise das Políticas de Incentivos Fiscais nos Municípios Brasileiros: o caso da instalação da Grendene no Município de Teixeira de Freitas-BA. Revista Catarinense da Ciência Contábil, 13(40), 37-53. doi:10.16930/22377662/rccc.v13n40p37-53

Pfeffer, J., \& Salancik, G. R. (2003). The external control of organizations: A resource dependence perspective. Stanford University Press.

Pinheiro, B. G., Luca, M. M. M., \& Vasconcelos, A. C. D. (2016). Conexões políticas nas maiores companhias listadas na BM\&FBovespa. REAd. Revista Eletrônica 
de Administração (Porto Alegre), 22(2), 394-418. doi: 10.1590/14132311.1622015 .60360

Riahi-Belkaoui, A. (2004). Politically-connected firms: are they connected to earnings opacity? Research in Accounting Regulation, 17, 25-38. doi:10.1016/s1052-0457(04)17002-1

Rodrigues Jr, M. S. (2003). A DVA como instrumento de mensuração da relação custo-benefício na concessão de incentivos fiscais: um estudo de casos (Tese de Doutorado). Universidade de São Paulo - USP, São Paulo, SP, Brasil. doi:10.11606/d.12.2003.tde-30082004-145853

Santos, R. L., \& Silveira, A. M. (2007). Board interlocking no Brasil: a participação de conselheiros em múltiplas companhias e seu efeito sobre o valor das empresas. Revista Brasileira de Finanças, 5(2), 125-163.

Santos, R. L., Silveira, A. M., \& Barros, L. A. (2012). Board interlocking in Brazil: directors' participation in multiple companies and its effect on firm value and profitability. Latin American Business Review, 13(1), 1-28. doi: 10.1080/10978526.2012.673419

Sarmento, E. D. M., \& Nunes, A. (2015). A evolução da concentração sectorial em Portugal entre 1995 e 2006: a perspetiva do índice de HerfindahlHirschman. Tourism \& Management Studies, 11(2), 146-158. doi:10.18089/tms.2015.11218

Schoorman, F. D., Bazerman, M. H., \& Atkin, R. S. (1981). Interlocking directorates: A strategy for reducing environmental uncertainty. Academy of Management Review, 6(2), 243-251. doi:10.5465/amr.1981.4287813

Shleifer, A., \& Vishny, R. W. (1997). A survey of corporate governance. The Journal of Finance, 52(2), 737-783. doi:10.1111/j.1540-6261.1997.tb04820.x

Silva, J. C. D., Xavier, W. G., Gambirage, C., \& Camilo, S. P. O. (2018). A Influência das Conexões Políticas no Custo de Capital e no Desempenho das Empresas Listadas na B3. BBR. Brazilian Business Review, 15(4), 317-330. doi: 10.15728/bbr.2018.15.4.1

Silveira, A. M., \& Barros, L. A. B. C. (2008). Determinantes da qualidade da governança corporativa das companhias abertas brasileiras. REAd: Revista Eletrônica de Administração, 14(3), 542-540.

Taveira, J. H. P. S. (2008). Conformidade do disclosure das subvenções governamentais nas empresas de capital aberto (Dissertação de Mestrado) Faculdades Ibmec. Rio de Janeiro.

Teixeira, E. A., Nossa, V., \& Funchal, B. (2011). O índice de sustentabilidade empresarial (ISE) e os impactos no endividamento e na percepção de risco. Revista Contabilidade \& Finanças, 22(55), 29-44. doi:10.1590/s151970772011000100003 
Weymer, A. S. Q., \& Castor, B. V. J. (2009). As estratégias de contratação de mão de obra no setor portuário à luz da teoria da agência. REBRAE, 2(3), 233-245. doi:10.7213/rebrae.v2i3.13466

Wong, L. H. H., Gygax, A. F., \& Wang, P. (2015). Board interlocking network and the design of executive compensation packages. Social Networks, 41, 85-100. doi: 10.1016/j.socnet.2014.12.002

Wu, W., Wu, C., Zhou, C., \& Wu, J. (2012). Political connections, tax benefits and firm performance: Evidence from China. Journal of Accounting and Public Policy, 31 (3), 277-300. doi:10.1016/j.jaccpubpol.2011.10.005

\section{CONTRIBUIÇÕES DOS AUTORES}

\begin{tabular}{|l|c|c|c|}
\hline \multicolumn{1}{|c|}{ Contribuição } & $\begin{array}{c}\text { André Carlos } \\
\text { Einsweiller }\end{array}$ & $\begin{array}{c}\text { Cristian Baú } \\
\text { Dal Magro }\end{array}$ & $\begin{array}{c}\text { Sady } \\
\text { Mazzioni }\end{array}$ \\
\hline $\begin{array}{l}\text { 1. Idealização e concepção do assunto e tema } \\
\text { da pesquisa }\end{array}$ & & $\checkmark$ & $\checkmark$ \\
\hline 2. Definição do problema de pesquisa & $\checkmark$ & $\checkmark$ & $\checkmark$ \\
\hline 3. Desenvolvimento da Plataforma Teórica & $\checkmark$ & $\checkmark$ & $\checkmark$ \\
\hline $\begin{array}{l}\text { 4. Delineamento da abordagem metodológica } \\
\text { da pesquisa }\end{array}$ & $\checkmark$ & $\checkmark$ & $\checkmark$ \\
\hline 5. Coleta de dados & $\checkmark$ & & \\
\hline $\begin{array}{l}\text { 6. Análises e interpretações dos dados } \\
\text { coletados }\end{array}$ & $\checkmark$ & $\checkmark$ & $\checkmark$ \\
\hline 7. Conclusões da pesquisa & $\checkmark$ & $\checkmark$ & $\checkmark$ \\
\hline 8. Revisão crítica do manuscrito & $\checkmark$ & $\checkmark$ & $\checkmark$ \\
\hline $\begin{array}{l}\text { 9. Redação final do manuscrito, conforme as } \\
\text { normas estabelecidas pela Revista. }\end{array}$ & $\checkmark$ & $\checkmark$ & $\checkmark$ \\
\hline 10. Orientação & & $\checkmark$ & $\checkmark$ \\
\hline
\end{tabular}

